N. Purandare, Senior Registrar in Psychiatry, University Hospital of South Manchester; L. Aitken, Consultant in Old Age Psychiatry, Stepping Hill Hospital, Stockport; P. Joshi, Consultant Psychiatrist, Stepping Hill Hospital; and ${ }^{*} \mathrm{C}$. S. Thomas, Consultant Psychiatrist,
Department of Psychiatry. University Hospital of South Manchester, Manchester M20 8LR

\title{
Enforcing treatment with clozapine: survey of views and practice
}

\author{
Stephen Pereira, Dominic Beer and Carol Paton
}

\begin{abstract}
Aim and method The aim of the study was to survey strategies for dealing with patients who refuse clozapine blood tests or tablets. One hundred and twenty-five psychiatric intensive care unit consultants were sent a questionnaire.

Results Thirty-nine (31\%) questionnaires were returned. Opinions and practices were diverse ranging from uncertainty around the legal right to enforce venepuncture, to the practice of slipping clozapine into a patient's drink without their knowledge.

Clinical implications There is need for an open debate of the relevant legal and ethical issues.
\end{abstract}

Neuroleptic treatment resistance in schizophrenia is a well acknowledged and not uncommon phenomenon (Morrison, 1996). Some severely ill people may be a danger towards others or themselves, or be at risk from severe self-neglect. These features arise directly from the person's illness. Clozapine is the only antipsychotic proven to be effective in people who have treatment-resistant schizophrenia (Kane, 1992). As well as having positive effects on aggression (Special Hospitals Treatment Resistant Schizophrenia Research Group, 1996) and suicidal behaviour (Meltzer \& Okayli, 1995), clozapine is associated with a very low incidence of extrapyramidal side-effects (Kane, 1992), which contributes towards its improved efficacy against negative symptoms. Although some subjects respond markedly to clozapine in the first few weeks of treatment, for others response may be slower and assessment periods of up to one year have been advocated (Kane, 1992). The tangible benefits that clozapine offers cannot be realised when subjects refuse treatment due to lack of insight or fear of blood tests.

Many psychiatric intensive care units (PICUs), challenging behaviour and forensic units have a small core group of patients who are referred to them out of despair; this may not only be due to acutely or chronically disturbed mental state and behaviour, but also due to the fact that every other intervention (e.g. maximum or above maximum British National Formulary doses of oral or depot neuroleptics, neuroleptic combinations, adjunct medications and psychological interventions) has been tried with limited or no success. In the meantime, the individual continues to behave dangerously towards others (e.g. destruction of property, assaults, arson, sexual disinhibition) or towards themselves (e.g. repetitive self-mutilation, severe self-neglect). Such ongoing behaviour poses the question of 'duty of care', not only to the patient themselves, but also to others at risk from these behaviours. In this small minority of patients who cannot be contained safely on open wards or sometimes even on PICUs, and who refuse to cooperate with clozapine treatment, the issue of enforcing blood tests and then subsequently, oral clozapine, may arise as one of the treatment options. As such interventions are more likely to be carried out on PICUs than on open admission wards, we sought the opinions of PICU consultants on the legal, ethical and practical considerations that may underlie such a treatment intervention and sought to determine if any units had practical experience of enforcing treatment with clozapine. 


\section{The study}

A questionnaire was sent to all consultant psychiatrists on the 110 PICUs identified in a previous survey of such facilities in the UK (Beer et al, 1997), and also to consultants on an additional 15 units which have since been identified (125 units in total). The questionnaire (available from the authors upon request) was divided into three sections: the first quantifying the number of patients refusing clozapine on the PICU; the second canvassing views on the theoretical acceptability of enforcing blood tests and oral treatment against a patient's will (defined as being when the patient was verbally and/or physically resistive) and the third determining whether there was any practical experience of such interventions.

The consultant was asked how many patients currently in their unit might benefit from treatment with clozapine, but were refusing blood tests and/or oral treatment. They were then asked whether they considered that taking blood against a patient's will was ever justified, bearing in mind perceived legal, ethical and practical considerations. If yes, the respondent was asked if 'duty of care' or risk to self or others, or any other reason would ever justify such an intervention. Further questions included how long it would be reasonable to try persuasion and/or education before resorting to enforced blood collection and who would be involved in the decision-making process.

The second section of the questionnaire asked if enforcing blood collection had ever been actively considered on their unit and if so. for how many patients. Questions around the practicalities of enforcing oral treatment with clozapine were also asked.

\section{Findings}

Thirty-nine questionnaires were returned (31\%). Twenty-two PICUs (56\% of responses) contained a total of 57 patients who were suitable for clozapine treatment but were refusing to cooperate with blood tests and/or oral treatment.

\section{Theoretical acceptability of enforcing venepuncture}

Almost an equal number of psychiatrists (27 and 28 respectively) believed they were ethically and legally justified in enforcing venepuncture if they believed their patient posed a significant risk to themselves or others $(n=22)$ or because they owed a duty of care $(n=18)$. Ten and nine respectively did not believe such an action was ever justified, and a further two were unsure. Views regarding the time span over which the patient's cooperation should be sought through educational initiatives and persuasion before considering enforced venepuncture ranged from two to 26 weeks (mode six weeks), with seven consultants believing that this period should be indefinite.

The decision to enforce venepuncture was considered to be a multi-disciplinary team decision by all 29 respondents who would not legally or ethically dismiss such a course of action, with in addition to the consultant, the following being involved: junior doctor $(n=29)$, consensus nursing view $(n=29)$, Mental Health Act second opinion doctor $(n=24)$, occupational therapist ( $n=16)$, social worker $(n=15)$, clinical psychologist $(n=13)$, relatives $(n=12)$ and pharmacist $(n=8)$. In one reply each, the patient's general practitioner, a forensic psychiatrist and a senior nurse would be consulted.

\section{Practical experience of enforcing venepuncture}

For a total of 21 patients in 14 units, discussions regarding enforcing venepuncture had taken place. The procedure was carried out in nine patients who were verbally resistive and four patients who were physically resistive. Active resistance continued for between one and eight weeks in these patients (mean three weeks). Reasons for not enforcing venepuncture after full discussion could be broadly divided into three groups: concerns over legal and ethical issues; staff issues such as nursing shortages and potential risks to staff; and patient issues such as the breakdown of the therapeutic alliance.

\section{Practical experience of enforcing oral} medication

The most common approach was to offer inducements such as increased social activities (five cases), money or cigarettes (two cases), the 'good will' of the Home Office (two cases) and no further intramuscular injections (one case). Six respondents enforced intramuscular medication each time oral clozapine was refused, five crushed the oral clozapine and offered it with a drink and a further one added it to a patient's drink without their knowledge.

\section{Comment}

The low response rate to our study (31\%) may reflect the fact that a third of PICUs do not have one consultant who is in overall control (Beer et al, 1997), and so there was no obvious person to complete the questionnaire. Other reasons could be the controversial nature of the topic. strong personal views, lack of awareness that clozapine treatment can be enforced under the Mental Health Act and the complexities that such a procedure might entail. 
The 39 PICU consultants who completed our questionnaire recalled 57 patients in their units who would benefit from clozapine but were refusing blood tests and/or oral treatment. If these figures are extrapolated to include PICU, challenging behaviour, high dependency and forensic units nationwide, a sizable cohort of patients would be involved.

In terms of the theoretical acceptability of enforcing venepuncture, the Mental Health Act Commission (1993) in a guidance note on the issue of non-consenting patients and clozapine concluded.

"Having considered the legal, pharmacological and medical advice received, the Commission concludes the administration of medical treatment under Part IV of the MHA includes such measures as are necessary and appropriate to ensure that the medicine is administered efficaciously and safely in accordance with good medical practice... with regard to clozapine treatment, this will include haematological monitoring by the Clozaril Patients Monitoring Service as required by the product licence".

It goes on to say

"Notwithstanding the authority to administer medical treatment in the absence of the patient's consent ... it is a matter for the individual judgement of the Responsible Medical Officer in conjunction with the clinical team to determine whether this authority should be exercised in an individual patient".

It states that this is an interim position.

Although this 'legal right' to enforce venepuncture under the Mental Health Act exists, a quarter of respondents seemed to be unaware of it and over a third had never considered using it. However, that something is legal does not mean that it is ethically acceptable and this is echoed in the literature. Durand et al (1992) illustrated the use of force "in a therapeutic manner" to overcome resistance in a nonconsenting patient but Ball \& Lipsedge (1991) "did not feel justified" in restraining their nonconsenting patients for weekly blood tests, although seven of their 12 patients had treatment-resistant schizophrenia and were eligible for clozapine treatment.

The issue of consent is crucial to the debate in clozapine refusers. Ideally "consent is only consent if truly informed" (Burns \& Harris, 1996). However, it has been argued that there are frequently doubts about a patient's capacity to comprehend relevant information and therefore to become "truly informed". In a study comparing patients with schizophrenia who refused to consent to treatment with those who did consent (Marder et al, 1983), refusers had significantly higher scores on the Brief Psychiatric Rating Scale (BPRS; Overall \& Gorham, 1962) for conceptual disorganisation, emotional withdrawal and unusual thought content. They were also more hostile, uncooperative and mistrustful of the treatment plan and more likely to believe that they were not ill. McEvoy et al (1981). in a study of people with chronic schizophrenia. found that $87 \%$ of patients did not believe they were mentally ill and $73 \%$ did not understand the need for medication. They suggested that many chronically ill patients lack sufficient insight into their condition to make sound judgements about medication and treatment. Zito et al (1985) showed that drug refusers were generally members of the young adult chronic psychiatric population, primarily suffering from schizophrenia, with multiple previous hospital admissions and evidence of persistent impairment in social functioning. This sub-population of patients is likely to gain most from clozapine treatment.

The usual reasons for refusing clozapine treatment centre around venepuncture and range from a fear of needles to delusions around blood. In a study of reasons for non-consent among 66 eligible patients, Bowen (1992) found that recruitment to an early trial of a clozapine analogue would have increased by nearly $50 \%$ if the venepuncture requirement could have been removed or fear of venepuncture overcome.

The Mental Health Act allows for the administration of antipsychotic medication to detained patients without their consent. Depot antipsychotics are often administered in this way and few mental health professionals would consider this to be unreasonable. Not providing patients with clinically indicated neuroleptics may be viewed as failing to provide a 'duty of care', as such patients are likely to have longer admissions to hospital, exhibit increased threatening and assaultative behaviour and have more frequent episodes of restraint and seclusion (Hoge et al, 1990). Such patients are also the cause of more staff injuries (Ciccone et al, 1993). It is inevitable that there will be increased use of both high-dose neuroleptics and polypharmacy to control disturbed behaviour, with all its attendant short- and long-term side-effects. This is all the more tragic as these very patients meriting a trial of clozapine, have either not responded to, or failed to tolerate these same neuroleptics in the past.

Although over half the units surveyed contained patients who were refusing treatment with clozapine, less than a third had discussed enforcing treatment and even fewer had followed this process through. Those who did not proceed because they thought there was no legal framework in which to do so, may be reassured by the Mental Health Act Commission's view. Those who thought that risks to staff were important should also consider the risks of an untreated patient. and those who considered the therapeutic alliance' to be of over-riding importance should also consider issues relating to 'duty of care'. 
In terms of practical experience of enforcing oral medication, there are considerable problems raised by some of the means adopted. If money or cigarettes are offered as inducements, then questions must be raised regarding the eligibility of other patients on the ward or even in the hospital to receive these same 'privileges'. Less problematic would be the incorporation of social activities as part of an individualised care plan in line with improvements in safety and mental state, although care must be taken not to deny the patient the opportunity to participate in therapeutic activities such as attending groups. Concerns have been raised by nursing staff regarding the practice of enforcing intramuscular medication each time clozapine is refused on the grounds that this can be viewed as a punitive approach. Crushing oral clozapine and observing ingestion poses no ethical problems as long as the patient is aware that it is being administered in this way. 'Slipping' clozapine into a patient's food or drink without their knowledge would be considered by most to be completely unacceptable.

The main issues raised in this survey relate not only to those of consent but also to the ethical and legal issues concerning the rights of refusal by patients with treatment-resistant schizophrenia who are incapable of consenting to treatment with clozapine, versus the duty of care owed to these patients and the quality of life they experience. Duty of care would also take into account the rights of fellow patients, nursing staff and other carers not to be assaulted. It would appear that there is an urgent need for open debate on these issues. This may be in the form of locally developed guidelines and/or national guidance from the Mental Health Act Commission.

\section{References}

BALL, C. J. \& L LPSEDGE, M. (1991) Use of clozapine (letter). Psychiatric Bulletin, 15, 645-646.

BeER, M. D., Paton. C. \& PEREIRA. S. (1997) Hot beds of general psychiatry: A national survey of psychiatric intensive care units. Psychiatric Bulletin, 21, 142-144.

BOWEN, T. (1992) Obtaining consent for treatment with clozapine (letter). Psychiatric Bulletin, 16. 239-240.
BURNS, A. \& HARRIS, T. (1996) Ethical issues in dementia. Psychiatric Bulletin. 20, 107-108.

Ciccone. R. J.. TOKOL, J. T. \& GiFT, T. E. (1993) Medication refusal and judicial activism: A re-examination of the effects of the Rivers decision. Hospital and Community Psychiatry, 32, 555-560.

DURAND. C. J., JARETZ. N. J.. LADDIS. A., et al (1992) Clozapine refusal (letter). Hospital and Community Psychiatry. 43, 85.

Hoge, S. K., Applebaum, P. S., LAWLer. T., et al (1990) A prospective multicentre study of patients' refusal of antipsychotic medication. Archives of General Psychiatry. 47. 949-956.

KANE. J. M. (1992) Clinical efficacy of clozapine in treatment refractory schizophrenia: an overview. British Journal of Psychiatry, 160 (suppl. 17), 41-45.

Marder. S. R., Mebane, A., Chient, C., et al (1983) A comparison of patients who refuse and consent to neuroleptic treatment. American Journal of Psychiatry. 140. 470-472.

MCEVOY, T. P., ALAND, T., WILSON. W., et al (1981) Measuring chronic schizophrenic patients' attitudes towards their illness and treatment. Hospital and Community Psychiatry. 32, 856-858.

MELTZER, H. \& OKAYL. G. (1995) Reduction of suicidality during clozapine treatment of neuroleptic-resistant schizophrenia: impact on risk-benefit assessment. American Journal of Psychiatry. 152, 183-190.

MENTAL HEALTH ACT COMMISSION (1993) Guidance on the Administration of Clozapine and Other Treatments Requiring Blood Tests Under the Provisions of Part IV of the Mental Health Act. Practice Note 1. Nottingham: Mental Health Act Commission.

MORRISON. D. P. (1996) Management of treatment refractory schizophrenia. Britlsh Journal of Psychiatry. 168 (suppl. 31), 15-20.

Overall, J. E. \& Gorham, D. R. (1962) The Brief Psychiatric Rating Scale. Psychological Reports, 10, 799-812.

SPECIAL HOSPTtALS TREATMENT RESISTANT SCHIZOPHRENIA RESEARCH GROUP (1996) Schizophrenla. violence. clozapine and risperidone: a review. British Journal of Psychiatry. 169 (suppl. 31). 21-30.

ZrTo, J. M.. RouTT, W. W., Mrrcheu. J. E., et al (1985) Clinical characteristics of hospitalised psychotic patients who refuse antipsychotic drug therapy. American Journal of Psychiatry, 142. 822-826.

*Stephen Pereira, Consultant Psychiatrist; Dominic Beer, Consultant Psychiatrist; and Carol Paton, Principal Pharmacist, Oxleas NHS Trust, Arsenal Locality CMHC, 132 Powis Street, Woolwich SE18 6NL

*Correspondence 